\section{S.Nava}

P. Navalesi

\title{
Bronchodilators and mechanical ventilation in COPD patients
}

\section{Emptying, pumping or both?}

Accepted:17 August 1999

S. Nava (๘)

Respiratory Intensive Care Unit,

Centro Medico di Riabilitazione di Montescano, IRCCS,

Fondazione S.Maugeri, I-27040 Montescano (PV), Italy

(e-mail: snava@fsm.it·Tel.: + 39-0385-247324 .

Fax: + 39-03 85-61386)

P. Navalesi

Centro di Riabilitazione "Villa Beretta",

Pulmonary Unit, Opedale Valduce, via N. Sauro 17,

I-23845 Costamasnaga (LC), Italy

Acute exacerbation in patients affected by chronic obstructive pulmonary disease (COPD) worsens airway obstruction and thereby produces a further rise in airflow resistance and dynamic hyperinflation. As a consequence, elevated airway resistance and intrinsic positive end-expiratory pressure (PEEPi) increase the load faced by the respiratory muscles, while hyperinflation reduces the force generation capacity of the diaphragm by shortening its fibres [1].

Pharmacological treatment, acting directly on the bronchial smooth muscle (beta ${ }_{2}$-agonists, anticholinergic agents and xanthines) [2] and reducing the inflammatory process (steroids and antibiotics) [3], may decrease airway obstruction and hyperinflation, thereby diminishing the mechanical load imposed on the respiratory muscles and improving diaphragmatic function. Unfortunately, during an episode of acute pump failure medical therapy works in about only $30 \%$ of the patients admitted to the ICU [4].

When the force-load balance is altered to a level such that respiratory muscle fatigue occurs, spontaneous breathing is no longer sustainable and mechanical ventilation is required. The ventilator acts as an extra pump put in series to the respiratory muscles and assumes the work of breathing entirely or in part, thereby reversing the unfavourable force-load balance. Furthermore, by reducing inspiratory effort, improving breathing pattern and correcting abnormal arterial blood gas tensions, mechanical ventilation may determine an improvement in respiratory muscle function through the mechanisms of rest, mechanical advantage due to reduced hyperinflation, better oxygenation and normalisation of acidosis.

As bronchodilators are a primary component of the treatment of COPD exacerbation $[5,6]$, they should not be discontinued when acute respiratory failure develops and mechanical ventilation is initiated. While steroids [7], xanthines [8] and antibiotics are usually parenterally administered, beta ${ }_{2}$-agonists are more effectively and safely given via a small volume nebuliser (SVN) or a metered-dose inhaler (MDI) connected to an appropriate spacer, even in mechanically ventilated patients [9].

Mouloudi and co-workers [10], in the paper published in this issue of the journal, studied nine patients within $72 \mathrm{~h}$ of the institution of ventilation. They found that $600 \mu \mathrm{g}$ of salbutamol delivered using MDI reduced airway resistance and PEEPi by an average of approximately $20 \%$ and $25 \%$, respectively, in eight of the nine $(88 \%)$ subjects. Their data qualitatively and quantitatively confirm the results of previous studies performed on mechanically ventilated COPD patients $[11,12,13]$.

It is interesting to observe that, in contrast to that described for the "acute" patients, only approximately $25-30 \%$ of stable COPD patients have significant bronchodilation, defined as an increase in the forced expiratory volume in $1 \mathrm{~s}\left(\mathrm{FEV}_{1}\right)$ of $12 \%$ or more or $200 \mathrm{ml}$ or more, after administration of beta ${ }_{2}$-agonists or anticholinergics. As a matter of fact, COPD is defined according to the major international guidelines "as a disease characterised by the presence of irreversible or only partially reversible airflow obstruction" [5,6]. The different degree of bronchodilation in the acute and chronic set- 
tings might depend on a more pronounced sensitivity to the drug during the acute phase since, during an episode of exacerbation, COPD has many histological features in common with asthma [14], which by definition is usually characterised by a significant response to bronchodilators.

The lack of sensitivity of $\mathrm{FEV}_{1}$ in assessing functional improvement after a reversibility test in stable "poorly reversible" COPD patients has very recently been a matter of study. Maesen and co-workers [15] found that measurements of airway resistance and work of breathing were more likely to reveal changes in airway calibre than $\mathrm{FEV}_{1}$ and this may be because the early airway collapse and subsequent airway decline due to the forced expiratory manoeuvre cause underestimation of "real" bronchodilator effect. However, as a matter of fact, we still do not know whether inhaled bronchodilators work beyond the acute phase in these mechanically ventilated COPD patients but, if so, they might be useful in the process of discontinuing mechanical ventilation, usually quite difficult in COPD patients. In this group of patients airway resistance and PEEPi have been shown to account for approximately $80 \%$ of the global burden [16]. Extrapolating the results of the study by Mouloudi et al. [10], inhaled beta ${ }_{2-}$ agonists would reduce the load imposed on the respiratory muscles by approximately $15-20 \%$, an amount that might be crucial in determining successful weaning. Indeed, in our experience sustained bronchodilator therapy may help to facilitate and accelerate the weaning process, although this has never been systematically tested.

Both SVN and MDI have been proven to induce significant reduction in airway resistance and dynamic hyperinflation, but MDI potentially offers advantages such as reduced risk of contamination and flow sensor damage, ease of administration, dose reliability and, possibly, cost reduction [9]. With MDI, however, adequate deposition of the drug in the lung may be affected by several technical aspects, including the ventilator settings. In in vitro studies end-inspiratory pause, duty cycle (Ti/Ttot), flow rate and tidal volume $\left(\mathrm{V}_{\mathrm{T}}\right)$ have been proposed as important determinants of the amount of drug actually delivered [17]. A previous work by Moloudi et al. excluded the possibility that an end-inspiratory pause of a few seconds could enhance the effect of the drug [18]. The study published in this issue of the journal [10] demonstrates that the response to salbutamol, delivered via MDI during controlled mechanical ventilation at constant flow, is not improved when $\mathrm{V}_{\mathrm{T}}$ and Ti/Ttot of the breath following drug administration are increased by $50 \%$. Minimising the importance of these manipulations, the work by Mouloudi makes the use of MDI in ventilated COPD patients more appealing because it is more applicable.

What is the reason for these discrepancies between in vitro and in vivo studies? It should be kept in mind that bench studies measure the quantity of drug inhaled and not its actual deposition and the amount of drug reaching the lungs does not necessarily mean actual bronchodilator response. The rise in inhaled drug observed using a larger $\mathrm{V}_{\mathrm{T}}$ in bench studies is, therefore, not necessarily followed by increased bronchodilatation. It has been shown that 4 puffs of albuterol ( $90 \mu \mathrm{g} /$ puff) can produce the same decay in airway resistance as 28 puffs in COPD patients, because of the limited airway reversibility of this population or the down-regulation phenomenon [19]. In the study by Mouloudi et al.[10] six puffs of salbutamol (100 $\mu \mathrm{g} / \mathrm{puff})$ were used. This dose, as suggested by the authors, might have produced maximal broncodilatation, which prevented any further beneficial effect being gained from $\mathrm{V}_{\mathrm{T}}$ manipulation. In addition, it should be remembered that in vitro studies have shown an increase in drug delivery for a $\mathrm{V}_{\mathrm{T}}$ greater than $500 \mathrm{ml}$ [17]. In Mouloudi's study [10] the so-called "normal" $\mathrm{V}_{\mathrm{T}}$ ranged from 450 to $660 \mathrm{ml}$, the mean being $582 \mathrm{ml}$. The authors ascertained the lack of positive effects when $V_{T}$ was increased, but could not exclude drawbacks due to $\mathrm{V}_{\mathrm{T}}$ reduction.

Like most of the previous in vivo studies, Mouloudi et al. [10] performed their investigation in subjects invasively ventilated in controlled mode (CMV). Forms of partial ventilatory support are preferred nowadays whenever possible and this is particularly the case for COPD patients, at least after the initial 12-24 h [20]. Fink et al. [17] observed that albuterol delivery in vitro was not different using total (CMV) or partial (A/C and PSV) forms of mechanical ventilatory assistance. By minimising the importance of some ventilatory settings (i.e. end-inspiratory pause, $\mathrm{V}_{\mathrm{T}}$, inspiratory time and duty cycle), the works of Mouloudi et al. [10-18] indirectly support the concept that the efficacy of the bronchodilator administered via MDI can be extended to the assisted ventilatory modes. If proven, this would increase the use of bronchodilators via MDI in the ICU. Indeed, non-invasive mechanical ventilation has been proven to be an effective treatment in acute respiratory failure due to COPD exacerbation [4] and, in our opinion, the possibility of delivering bronchodilators via MDI during this ventilatory mode deserves future investigation.

In summary, should we start thinking that beside pumping, emptying is also a major goal to achieve in mechanically ventilated COPD patients? To date we have scientific evidence that both mechanical ventilation and bronchodilators are important weapons that we have to use in these critically ill patients. While, in several studies, the choice of different strategies of mechanical ventilation have been shown to have an impact on the outcome, facilitating for example the process of weaning while reducing complications [20], we have no data concerning the use of bronchodilators. It is nevertheless surprising that in the most important randomised clinical trials $[20,21,22,23]$ comparing different 
methods of weaning, there is no mention at all of the inhalation therapy, if any, that the patients were receiving. If, as suggested by Mouloudi's study [10], the delivery of salbutamol may reduce the global burden of the respiratory pump by about $20 \%$, this may profoundly influence, at least in COPD patients, the weaning results, so that some of the previously reported data may need to be reconsidered. It is time, therefore, to design randomised and controlled clinical studies to assess whether bronchodilators, besides having a physiological effect, may also influence survival, duration of mechanical ventilation and ICU stay and the related costs.

\section{References}

1. Similowski T, Milic-Emili J, Derenne JP (1996) Respiratory mechanics during acute respiratory failure of chronic obstructive pulmonary disease. In: Derenne JP, Whitelaw WA, Similowski T (eds) Acute Respiratory Failure in Chronic Obstructive Pulmonary Disease. Marcel Dekker, New-York, pp 23-46

2. Karpel JP (1991) Bronchodilator responses to anticholinergic and beta-adrenergic agents in acute and stable COPD. Chest 99: 871-876

3. Niewoehner DE, Erbland ML, Deupree RH, Collins D, Gross NJ, et al. (1999) Effect of systemic glucocorticoids on exacerbations of chronic obstructive pulmonary disease. $\mathrm{N}$ Engl $\mathrm{J}$ Med 340: 1941-1947

4. Brochard L, Mancebo J, Wysocki M, Lofaso F, Conti G, Rauss A, et al. (1995) Noninvasive ventilation for acute exacerbations of chronic obstructive pulmonary disease. $\mathrm{N}$ Engl $\mathrm{J}$ Med 333: 817-822

5. ATS standards for the diagnosis and care of patients with chronic obstructive pulmonary disease (1995) Am J Respir Crit Care Med 152: S78-S121

6 . The BTS guidelines for the management of chronic obstructive pulmonary disease (1997) Thorax 52 Suppl 5: S1-S28

7. Rubini F, Rampulla C, Nava S (1994) Acute effect of corticosteroids on respiratory mechanics in mechanically ventilated patients with chronic airflow obstruction and acute respiratory failure. Am J Respir Crit Care Med 149: 306-310

8. Poggi R, Brandolese R, Bernasconi M, Manzin E, Rossi A (1989) Doxofylline and respiratory mechanics. Short-term effects in mechanically ventilated patients with airflow obstruction and respiratory failure. Chest 96: 772-778
9. Dhand R, Tobin M (1997) Inhaled bronchodilator therapy in mechanically ventilated patients. Am J Respir Crit Care Med 156: 3-10

10. Mouloudi E, Katsanoulas K, Anastasaki M, Hoing S, Georgopoulos D (1999) Bronchodilators delivery by metereddose inhaler in mechanically ventilated COPD patients: influence of tidal volume. Intensive Care Med 25: 1215-1221

11. Bernasconi M, Brandolese R, Poggi R, Manzin E, Rossi A (1990) Dose-response effects and time course of effects of inhaled fenoterol on respiratory mechanics and arterial oxygen tension in mechanically ventilated patients with chronic obstructive pulmonary disease. Intensive Care Med 16: 108-114

12. Fernandez A, Lazaro A, Garcia A, Aragon C, Cerda E (1990) Bronchodilators in patients with chronic obstructive pulmonary disease on mechanical ventilation: utilisation of metered-dose inhalers. Am Rev Respir Dis 141: 164-168

13. Guerin C, Chevre A, Dessirier P, Poncet T, Becquemin MH, et al. (1999) Inhaled fenoterol-ipratropium bromide in mechanically ventilated patients with chronic obstructive pulmonary disease. Am J Respir Crit Care Med 159: 1036-1042

14. O'Byrne PM, Postma DS (1999) The many faces of airway inflammation. Asthma and chronic obstructive pulmonary disease. Am J Respir Crit Care Med 159: S41-S66

15. Maesen BLP, Westermann CJJ, Duurkens VAM, Van den Bosch JMM (1999) Effects of formoterol in apparently poorly reversible chronic obstructive pulmonary disease. Eur Respir J 13: $1103-1108$

16. Appendini L, Purro A, Patessio A, Zanaboni S, Carone M, et al. (1996) Partitioning of inspiratory muscle workload and pressure assistance in ventilator-dependent COPD patients. Am J Respir Crit Care Med 154: 1301-1309
17. Fink JB, Dhand R, Duarte AG, Jenne JW, Tobin MJ (1996) Aerosol delivery from a metered-dose inhaler during mechanical ventilation. An in vitro model. Am J Respir Crit Care Med 154: 382-387

18. Mouloudi E, Katsanoulas K, Anastasaki M, Askitopoulou E, Georgopoulos D (1998) Bronchodilator delivery by metered-dose inhaler in mechanically ventilated COPD patients: influence of end-inspiratory pause. Eur Respir J 12: 165-169

19. Dhand R, Duarte AG, Jubran A, Jenne JW, Fink JB, et al. (1996) Dose-response to bronchodilator delivery by metered-dose inhaler in ventilator-supported patients. Am J Respir Crit Care Med 154: 388-393

20. Nava S, Ambrosino N, Clini E, Prato M, Orlando G, et al. (1998) Noninvasive mechanical ventilation in the weaning of patients with respiratory failure due to chronic obstructive pulmonary disease. A randomized, controlled trial. Ann Intern Med 128: 721-728

21. Brochard L, Rauss A, Benito S, Conti G, Mancebo J, et al. (1994) Comparison of three methods of gradual withdrawal from ventilatory support during weaning from mechanical ventilation. Am J Respir Crit Care Med 150: 896-903

22. Esteban A, Frutos F, Tobin MJ, Alia I, Solsona JF, et al. (1995) A comparison of four methods of weaning from mechanical ventilation. Spanish Lung Failure Collaborative Group. N Engl J Med 332: $345-350$

23. Ely WE, Baker AM, Dunagan DP, Burke HL, Smith AC, et al. (1996) Effect on the duration of mechanical ventilation of identifying patients capable of breathing spontaneously. N Engl J Med 335: 1864-1869 